\title{
NeurolS: Neuroscientific Approaches in the Investigation and Development of Information Systems
}

DOI 10.1007/s12599-010-0130-8

\section{The Authors}

Prof. Dr. Peter Loos ( $\varangle)$

Institute of Business Information

Systems

Saarland University

Struhlsatzenhausweg 3

66123 Saarbrücken

Germany

loos@iwi.uni-sb.de

\section{René Riedl}

Gernot R. Müller-Putz

Jan vom Brocke

Fred D. Davis

Rajiv D. Banker

Pierre-Majorique Léger

Published online: $2010-10-20$

This article is also available in German in print and via http://www. wirtschaftsinformatik.de: Loos P, Riedl R, Müller-Putz GR, vom Brocke J, Davis FD, Banker RD, Léger P-M (2010) NeurolS: Neurowissenschaftliche Ansätze in der Erforschung und Gestaltung von Informationssystemen. WIRTSCHAFTSINFORMATIK. doi: 10.1007/ s11576-010-0249-8.

(c) Gabler Verlag 2010

\section{Introduction}

For several years, there has been an increased application of neuroscientific approaches in the North American Information Systems (IS) discipline. Theories and methods from neuroscience contribute to a better understanding of human behavior. Since IS tries to explain human behavior in the use of information systems, neuroscientific approaches can also contribute to a growth of knowledge. In this regard, Dimoka et al. (2007, p. 13) stated in one of the first publications on this matter: "It is just hard to believe that a better understanding of brain

functioning will not lead to better IS theories."

Against the background of the increasing internationalization of business and information systems engineering (BISE), the following discussion deals with the issue of "NeuroIS". The need for a discussion on NeuroIS is reinforced by the fact that neuroscientific approaches also gain in importance in other business and social sciences (e.g., neuroeconomics, Camerer et al. 2005). In the years 2009 and 2010, there have already been two relevant scientific symposia in Austria which explicitly focused on NeuroIS. At this year's conference "Gmunden Retreat on Advances in NeuroIS" (see http:// www.NeuroIS.org), which was attended by a number of experts from the German-speaking BISE, opportunities and challenges of NeuroIS were discussed. Here, both methodical and theory-related issues were on the agenda. A central conclusion of the conference was that neuroscientific approaches can help not only to explain human behavior in dealing with information, but are also relevant for design-oriented BISE scientists. This circumstance is of particular interest for BISE researchers in the German-speaking area as one of their strengths is the design and concept of new innovative technologies.

In order to achieve a broad perspective on the issue in the course of this discussion, both North American scientists as well as representatives of the Germanspeaking BISE were invited to comment on the topic. The following authors accepted my invitation to this discussion (in alphabetical order):

- Prof. Rajiv D. Banker, Merves Chair in Accounting and Information Technology, Fox School of Business and Management, Temple University, USA;

- Prof. Jan vom Brocke, Hilti Chair in Business Process Management, University of Liechtenstein;

- Prof. Fred D. Davis, David D. Glass Chair in Information Systems, Sam M. Walton College of Business, University of Arkansas, USA;
- Prof. Pierre-Majorique Léger, Associate Professor am Department of Information Technologies, HEC Montréal, Canada;

- Prof. Gernot R. Müller-Putz, Associate Professor at Institute of Knowledge Discovery, Laboratory of BrainComputer Interfaces, Graz University of Technology, Austria;

- Prof. René Riedl, Associate Professor at Department of Business Informatics - Information Engineering, University of Linz, Austria.

The six authors comment on various facets of NeuroIS that appear relevant and important for BISE in four contributions.

René Riedl and Gernot R. Müller-Putz illustrate that neuroscientific approaches may be used to explain BISE-related phenomena as well as for the design of innovative information systems, based on three specific examples. For instance, the authors report on a laboratory experiment based on eBay websites. In addition, the authors refer to research and development projects in the IT industry which were presented to the public as prototypes in recent years.

Jan vom Brocke comments on the role of neuroscience in design-oriented BISE research, arguing that neuroscientific approaches can not only be used in behavioral research. Building on the potentials of design-oriented research, vom Brocke distinguishes two major research streams: research by design and research on design. As to the former, he discusses the role of neuroscientific methods and theories in the development and evaluation of artifacts. As to the latter, he argues that neuroscientific approaches can also be used for generating and refining design theories.

Fred D. Davis and Rajiv D. Banker focus on the integration of neuroscientific approaches to technology acceptance research. Since the 1980s, works on the technology acceptance model (TAM) have been published in large numbers. The authors find, however, that in recent years only incremental advances in 
knowledge were achieved on the basis of questionnaire studies. Through the use of knowledge about conditions and processes in the human brain as well as the application of modern imaging techniques like functional magnetic resonance imaging (fMRI), a new perspective on technology acceptance research has been opened up that promises substantial progress.

Pierre-Majorique Léger then presents ERPsim, an innovative approach to learning for teaching enterprise resource planning skills. It is especially noteworthy that this approach makes use of neurophysiological methods of measurement (e.g., galvanic skin response) in order to capture emotional reactions of SAP system users in real time. These neurophysiological data can be evaluated using a triangulation with data from questionnaire surveys and observations, resulting in a deeper understanding of the use of ERP systems.

This discussion intends to stimulate the scientific discourse on the application, potentials, and risks of neuroscientific approaches in BISE. The scientific community is invited to participate in this discussion. If you would like to comment on this topic or another article of the journal Business \& Information Systems Engineering (BISE), please send your contribution (max. 2 DIN A4 pages) to the editor-in-chief, Prof. Hans Ulrich Buhl, University of Augsburg, HansUlrich.Buhl@wiwi.uni-augsburg.de.

Prof. Dr. Peter Loos IWi at DFKI

Saarland University, Germany

\section{On the Potential of Neurols: Three Examples}

In our following article on "NeuroIS" we outline three examples, based on a NeuroIS definition, that can shed light on the potential of NeuroIS for research and development in BISE. The contribution ends with a brief conclusion.

At the "Gmunden Retreat on the Foundations of NeuroIS" in 2009, the following definition of NeuroIS was developed (cf. Riedl et al. 2010a, p. 245): "NeuroIS is a subfield in the IS literature that relies on neuroscience and neurophysiological theories and tools to better understand the development, use, and impact of information technologies (IT). NeuroIS seeks to contribute to (i) the development of new theories that make possible accurate predictions of IT-related behaviors, and (ii) the design of IT artifacts that positively affect economic and non-economic variables (e.g., productivity, satisfaction, adoption, well being)."

The definition includes the explanation of the behavior of information systems as well as their design, and thus meets the dual nature of business and information systems engineering (BISE). On the one hand, the three examples outlined below focus on the explanation of IT behavior, i.e. on answering a why-question (Example 1). On the other hand, they focus on the design of systems (Examples 2 and 3 ).

\subsection{Example 1 (eBay): Gender and Trust in the Brain}

The investigation of gender-specific differences in the use of information systems is an important topic. One insight of past research is that there are significant differences between men and women in IT behavior. A major difference is, for example, that women generally perceive a higher risk than men when shopping on the Internet. Moreover, women often also assess the trustworthiness of online shopping as lower than men do.

These gender-specific differences in IT behavior raise the question of why these differences exist. Riedl et al. (2010b) analyzed this issue by applying fMRI (functional magnetic resonance imaging) and investigated brain activation differences between men and women when processing trustworthy and untrustworthy eBay offers. The authors found that women primarily activated limbic brain areas (which typically focus on processing emotions) and men tended to use prefrontal brain structures (which rather focus on rational thinking). Another result is that women activated more brain structures than men, particularly because women process more information and do this in a more comprehensive and detailed manner than men, who in turn process information in a more selective and holistic way.

The finding that gender-related differences exist in neural information processing, which are also manifest in significant behavioral differences, has implications for the design of information systems. The content of the presented in- formation, such as product descriptions in online shops, but also the type of information presentation (textual, graphical, or a combination) as well as the design and colors of user interfaces may be adapted according to the user's sex in order to positively influence major variables, such as technology acceptance or user satisfaction.

\subsection{Example 2 (Microsoft): Interaction Between Brain and Computer}

A few years ago, a patent application entitled "Using electroencephalograph signals for task classification and activity recognition" by Microsoft became public (Tan and Lee 2006). The goal is to identify which cognitive task is performed by a computer user at a certain point in time by means of brain activity measured through electroencephalography (EEG). To achieve this goal it is necessary, among other things, to assign statistically distinguishable EEG patterns to certain mental states of a user, particularly because the mental states prevailing in the brain of a user and the resulting EEG patterns are again used as data for the processing in technical systems (Wolpaw et al. 2002).

Business applications of such braincomputer interfaces (BCI) are just about to emerge. Long-term objectives of these research and development activities primarily include:

- Automation of process steps in administrative processes; for example, future systems may identify the mental state of a user and start operations without an input device, such as a computer mouse, or users may intentionally activate mechanical processing tasks by certain thoughts.

- Increasing the usability of systems; for example, an automatic adaptation of the content and type of representation of information as well as the design and the colors of user interfaces could be based on the mental state of the user.

The achievement of both objectives can contribute to an increased productivity of users, an essential factor in the use of systems in the business context. To date, BCI systems are developed and used mainly in the medical field. Especially for people who are completely paralyzed and cannot speak, but who are at the same time cognitively unimpaired, BCI systems form a way to communicate (Birbaumer et al. 1999; Dornhege et al. 2007; Pfurtscheller et al. 2008; Müller-Putz et 
al. 2010). Other recent applications show that thought-controlled navigation in a simple form is possible in virtual worlds (e.g., navigation to the left or right, up or down).

An overall assessment of developments in the field of brain-computer interfaces, however, shows that commercial products do not exist yet. This means that the available systems are always associated with accompanying activities of engineers who implement and run the systems at the user's site. It follows that the mentioned long-term objectives of the research and development activities in the field of BCI must currently be considered as a vision rather than a reality. Nevertheless, we believe that BCI systems have high potential particularly in the field of human-computer interaction.

\subsection{Example 3 (Philips): Financial Information Systems and Emotions}

More and more people trade securities from home via the Internet. Efficient and secure systems form the basis of these transactions. Findings of empirical research show that financial decisions are not optimally made if the decision-maker is highly emotionally charged (e.g., by fear or greed). Philips developed a prototype information system and presented it to the public in 2009 under the title "Rationalizer concept: An emotion mirroring system for online traders." The system measures the emotions of a user on the basis of galvanic skin response and it warns a user if he is too emotionally charged. The more agitated a person is, the more sweat is produced, which in turn increases the conductance of the skin. The system's warning in case of strong emotion can be used to abstain from financial transactions at a certain point in time. The assumption is that the use of the system reduces unfavorable financial decisions.
The system consists of two components, a bracelet that is attached to the wrist and measures emotions via skin conductance, and a display device that displays the strength of emotions by light patterns and colors. The display device has the design of a bowl, which, when standing next to a computer, appears hardly disturbing. The simplicity of the components themselves and their use make the system predestined for its practical use, a fact that is less the case with EEG (because electrodes must be attached to the scalp) and with fMRI (for which people must lie fixed in a machine during the measurement of brain activity).

\subsection{Conclusion}

We outlined three examples elucidating the diverse potentials of the use of neuroscientific approaches for the explanation and design of information systems.

We believe that neuroscientific theories and methods enrich BISE and thus contribute to the long-term growth of knowledge, but we perceive neuroscientific approaches to have a complementary nature to existing theories and methods. In addition, it is necessary to meet the challenges associated with the use of neuroscientific approaches. Some key challenges have been discussed in the literature already, as for example sample size, external validity, moral and ethical concerns as well as cost aspects (cf. Riedl et al. 2010a).

René Riedl

Department of Business Informatics University of Linz, Austria

Gernot R. Müller-Putz Institute of Knowledge Discovery Graz University of Technology, Austria

\section{On the Role of Neuroscience in Design-Oriented Research}

\subsection{Introduction}

Design-oriented research concerns the design process of IT artifacts, i.e., constructs, models, methods and instantiations (March and Smith 1995; Hevner et al. 2004). The design of process models at an enterprise-wide scale provides a good example for today's business practice. It comes along with several challenges like: What modeling language/technique is the most appropriate? What is the right level of detail? How to safeguard the comprehensibility of process models developed for people from different cultural backgrounds? And, to what extent do they perceive these models as useful for their individual work at all?

In design-oriented BISE research, particularly two lines of inquiry to approaching such issues can be distinguished: On the one hand, artifacts (e.g., process variations) can be designed and evaluated in an iterative process in order to identify solutions that will prove to be useful in certain types of applications. On the other hand, the study of the design process itself can be at the core of designoriented research (e.g., design decisions in the modeling process). Table 1 opposes the two approaches to one another, referred to as research by design and research on design. The table further illustrates the benefits that might be realized through the use of neuroscientific methods.

\subsection{Research by Design}

Research by design in particular focuses on the design and evaluation of artifacts. That being said, the outcome of such research is a specific artifact, together with insight about its usefulness in a certain application context (e.g., to what extent did a process description developed in a certain modeling language prove useful

Table 1 Roles of neuroscientific methods and theories in research by design and research on design

\begin{tabular}{|c|c|c|}
\hline & Research by Design & Research on Design \\
\hline Approach & Carrying out design and evaluation processes & Reflecting on design and evaluation processes \\
\hline Statement & Relation between artifact and perceived utility & $\begin{array}{l}\text { Relations between design decisions and the quality of the artifact } \\
\text { as well as quality of the artifact and results }\end{array}$ \\
\hline Objective & Development of innovative and purposeful artifacts & Acquisition of knowledge about design and evaluation processes \\
\hline \multirow{2}{*}{$\begin{array}{l}\text { Role of neuroscientific } \\
\text { methods and theories }\end{array}$} & - Evaluation of artifacts & - Development of new design theories \\
\hline & - Use of theories from neuroscience & - Evaluation of existing design theories \\
\hline
\end{tabular}


in a particular case organization?). This approach, which has been widely spread in the German-speaking BISE community in the past few years, appears particularly suitable when only a few success factors of the design process can be determined ex ante (e.g., the technical, cultural, task-specific, and demographic backgrounds of the employees). Neuroscience can provide both methods evaluating and theories grounding the design of IT artifacts.

\subsubsection{Evaluation of Artifacts}

At the most basic level, the evaluation of an artifact allows the researcher to make statements about its usefulness. Fellow researchers have proposed the use of traditional qualitative and quantitative approaches, such as case study research and simulations, for the evaluation of artifacts (Hevner et al. 2004). Not only in design-oriented research, however, the use of such methods goes along with several challenges (Riedl et al. 2010). The results of observations and interviews, for example, are often subjective, as they might be influenced by the hidden intentions of the informants. In contrast, measurement methods of neuroscience provide innovative and more objective ways to monitor the actual cognitive effects of individual recipients. Past PET (positron emission tomography) studies, for example, measured cognitive load (e.g., Haier et al. 1992), and fMRI (functional magnetic resonance imaging) was used to identify specific brain regions that are associated with "cognitive conflict" (e.g., Botvinick et al. 2004), such as the anterior cingulate cortex (ACC). Hence, neuroscience could be used to further investigate various phenomena related to the perception of artifacts.

Both costs and authenticity associated with neuroscientific measurements require specific attention. As to the former, it can be expected that technological progress will enable cheaper and more mobile measurements in the future. Today, however, there are already some "lightweight" measurement methods (e.g., galvanic skin response, pupil behavior, heart rate), which can complement the more sophisticated techniques such as fMRI. Such techniques make it possible to gain physiometrical information related to the use of artifacts not only in experimental settings but also in the professional work environment. As to the latter, the legitimate use of the results obtained through neuroscientific measurements appears similarly important. This not only refers to ethical considerations, but further concerns the interpretation of results. That being said, direct measurements in the head (or body) should not be considered more objective and superior to traditional approaches per se. Researchers should rather bear in mind that such results refer to individual subjects (usually about 15 to 20 subjects in fMRI studies) and require thorough interpretation. Neuroscientific measurements should thus rather be used to complement the results of traditional methods in the sense of triangulation.

\subsubsection{Use of Theories from Neuroscience}

On many issues related to the perception (or creation) of artifacts, neuroscientific findings already exist that can be used in research by design (e.g., the above mentioned findings regarding "cognitive load" and "cognitive conflict"). This is especially worth mentioning as these results can inform the design of artifacts without conducting any additional neuroscientific measurements. The selection process of modeling languages, for example, may be grounded in knowledge about the information processing capacity of the recipients (e.g., regarding the processing of objects, numbers, and other characters). Studies on different cognitive styles could also be used in order enable the refinement of models in a rather multiperspective way. Similarly, findings on the rational and creative cognitive performance could provide a valuable basis for the design of models. In this context, Riedl (2009), for example, highlights the question to what extent the cognitive style of people may have an influence on the choice of either object-oriented or flow-oriented languages. A wide range of similar questions can be studied accordingly using neuroscientific theories, methods, and tools.

Once NeuroIS studies, as outlined above, are increasingly carried out in BISE research, an evaluation and further development of neuroscientific theories can also be achieved. This is particularly the case if questions arise from BISE research that have not been studied in neuroscience so far. This consideration leads to the second main application domain of NeuroIS in design-oriented research: the design (and further development) of theories in "research on design".

\subsection{Research on Design}

Research on design studies the design processes of artifacts rather than artifacts as such (e.g., how to design process models in a specific notation?). This approach to design-oriented research is particularly discussed in studies on design theories (e.g., Gregor and Jones 2007; Walls et al. 2004). A design theory can be considered a specific type of theory that provides normative statements about typical design processes (i.e., "how to do something"; Gregor 2006, p. 628).

As to the various influences relevant in different design processes, multiple design theories are very likely to be needed that may serve as a pool of theories. With each theory relating to a certain aspect of design a combination of different theories may help to understand a certain design process appropriately. Following this approach, methods of neuroscience may particularly contribute to research on design by both further developing and evaluating design theories.

\subsubsection{Development of New Design Theories}

The evaluation of artifacts with the help of methods from neuroscience can provide new insight on design processes of artifacts. Such findings may include specific design issues particularly relevant in BISE research (e.g., the selection of modeling languages or methods). Here, the focus should not to be limited to the perception of artifacts. It will also be interesting to see how earlier phases of the design process can be studied, for example, the creative development and collaborative discussion of possible solutions.

\subsubsection{Evaluation of Existing Design Theories}

Finally, also contemporary insights about design processes can be evaluated and possibly extended by neuroscientific methods. This holds not only for design theories in the strict sense, but also for other theory types (e.g., the Technology Acceptance Model). Here, it again appears particularly promising - just as for research by design - to combine traditional research strategies and methods with neuroscientific approaches to accomplish our findings. 


\subsection{Conclusion}

Design-oriented research in BISE includes both the implementation and evaluation of artifacts and the reflections on such an endeavor. These two perspectives on design-oriented research - research by design and research on design - are intertwined. In research by design, both artifacts and design theories can be evaluated with the help of neuroscientific approaches. In research on design, it appears reasonable to first assess how existing neuroscientific theories can contribute to the development and evaluation of design theories.

In particular, interdisciplinary research projects appear suited to make best use of neuroscientific methods. BISE researchers can then pose questions for which appropriate experimental designs are developed together with neuroscientists. On the basis of such cooperation, a more intense methodological discussion on NeuroIS may take place in the medium term. This, however, particular requires the development of generally accepted quality criteria and procedures that can be used both in the work of authors and reviewers. As in other areas, the mere application of neuroscientific measurement techniques will certainly not be sufficient. Instead, BISE researchers will have to learn to use the new possibilities in a way that enables them to develop new knowledge surrounding the design and use of information systems. Then, the potentials are enormous as neuroscience provides an entirely new kind of approach to study our objects of research in IS.

Jan vom Brocke

Martin Hilti Chair in

Business Process Management University of Liechtenstein

\section{The Technology Acceptance Model and Cognitive Neuroscience}

The Technology Acceptance Model (TAM) is a leading theoretical model for explaining, predicting, and influencing information technology adoption. TAM theorizes that adoption is driven by users' intentions, and that intentions are influenced by users' perceptions of systems' usefulness and ease of use. Practical interventions such as the choice of system design characteristics and training techniques can influence adoption due to their influence on perceived usefulness and ease of use. Over the more than twenty years since its introduction, there have been numerous extensions and refinements to the basic model, including adaptations to specific contexts (sometimes referred to as TAM++; Venkatesh et al. 2007). Nevertheless, several recent reviews observe that the core model is powerful and parsimonious.

Despite the success of TAM++, its explanatory power is far from perfect, and it is increasingly difficult to gain new insights about technology acceptance using traditional behavioral experiments and surveys. Therefore some researchers have begun to leverage cognitive neuroscience knowledge and techniques to try to advance knowledge in this area.

A recent preliminary study (Dimoka and Davis 2008) sought to identify the neural correlates of the TAM constructs. Six participants were asked to browse two e-commerce websites, one low and the other high in usefulness and ease of use. Then the participants responded to several traditional self-report questions about their perceived usefulness and perceived ease of use of each website while undergoing fMRI scanning. For the positive website, usefulness questions activated the caudate nucleus and anterior cingulate cortex, which are associated with reward processing; for the negative website usefulness questions activated the insular cortex, which is associated with negative emotions regarding fear of loss. For both websites, questions about ease of use activated the dorsolateral prefrontal cortex, which is associated with sequential execution of operations during cognitive processing. There were significant differences in activation between the positive and negative websites for the usefulness areas, and a borderline significant difference for the ease of use area. In turn, the activation of these areas predicted post-scan self-reports of purchase intentions $\left(R^{2}=0.48\right)$. This study illustrates the feasibility of identifying neural correlates of usefulness and ease of use that are influenced by the quality differences between two websites, are consistent with self-reported values of these perceptions, and which in turn are predictive of behavioral intentions. While this is a hopeful starting point, IS researchers are looking to cognitive neuroscience to advance beyond the already established determinants of technology adoption.
TAM theorizing has been strongly influenced by models from social psychology that emphasize conscious, deliberate decision making processes, such as the Theory of Reasoned Action (TRA) and the Theory of Planned Behavior (TPB). However, recent theorizing in psychology, behavioral economics, and neuroscience (e.g., Camerer et al. 2005; Lieberman 2007) indicates that behavior is actually driven by two different systems, a controlled system, sometimes called the $\mathrm{C}$ system referring to the " $\mathrm{c}$ " in reflective, and an automatic system, sometimes called the X system referring to the " $\mathrm{X}$ " in reflexive. Whereas the $\mathrm{C}$ system is conscious, serial, effortful, and slow, the $\mathrm{X}$ system is unconscious, parallel, effortless, and fast. Contrary to traditional theorizing, the X system has often been found to be as important, or even more important, than the $\mathrm{C}$ system in driving behavior. Further, intelligent human behavior is usually better understood in terms of the interplay between the $\mathrm{C}$ and $\mathrm{X}$ systems rather than either the $\mathrm{C}$ or $\mathrm{X}$ system in isolation. Perhaps due to their reliance on conscious self-reported constructs, traditional intention models such as TAM, TRA, and TPB have emphasized the $\mathrm{C}$ system and deemphasized the $\mathrm{X}$ system.

The quest for deeper knowledge about the $\mathrm{X}$ system and its relationship to the $\mathrm{C}$ system is one key reason why IS researchers are looking to cognitive neuroscience to advance TAM research. The $\mathrm{X}$ system is highly relevant for many constructs and phenomena that TAM researchers are increasingly interested in, such as habit and automaticity, cognitive skill, emotions, social influence, multi-tasking, attentional control, implicit learning, knowledge collaboration, and goal regulation. In general, cognitive neuroscience promises to open up new avenues for advancing knowledge about the key processes driving user adoption behavior and offer new insights into how to design better systems by exploiting new insights about the mental processes underlying their use.

Such dual processing systems as the $\mathrm{X}$ and $\mathrm{C}$ systems also help explain the interaction between individuals as captured in behavioral economics models that include both self-interest and regard for preferences of others (Fehr and Schmidt 1999). Neuroscience studies are beginning to indicate separation in the parts of the brain that process self-interested and other-regarding preferences that lead to 
social concerns such as fairness in economic decisions. Understanding how the neural processes giving rise to the different preferences interact with each other can help us predict technology adoption decisions that simultaneously account for preferences of multiple individuals in social settings (Ho and Su 2010).

Bagozzi (2007) argues that future research efforts to broaden and deepen TAM should address the intentionbehavior linkage (in particular goal setting and self-regulation), group, cultural, and social aspects of technology acceptance, and the role of emotions. These are all areas where new insights and methods from cognitive neuroscience offer promising avenues for progress. Examples of constructs that appear promising for investigation using cognitive neuroscience include enjoyment, flow, cognitive absorption, skill, habit, fatigue, boredom, trust, risk, frustration, anger, cognitive workload, vigilance, disengagement, multitasking, and technostress.

Cognitive neuroscience is refining and advancing the theoretical foundations of traditional reference disciplines for IS research, including psychology, economics, and organizational behavior. It should be possible to take advantage of knowledge flowing from cognitive neuroscience for refining IS theories and hypotheses which can then be tested using traditional behavioral methods, without necessarily relying on brain measurements per se. Neuroscience techniques further open up opportunities for measuring important constructs that are difficult or impossible to tap using traditional approaches.

Fred D. Davis

Sam M. Walton College of Business University of Arkansas, USA

Rajiv D. Banker Fox School of Business and Management Temple University, USA

\section{ERPsim: A Simulation Platform for Experimental Research in Neurols}

One of the challenges in using an experimental approach in NeuroIS research is the difficulty to create realistic IT organizational environments where end-users' behaviors can be monitored and analyzed in real time. A simulation technology developed at HEC Montréal, called ERPsim, was designed to address this challenge (Léger 2006; Léger et al. 2007). This technology allows for the simulation of realistic collaboration scenarios through the use of a real-life ERP system. Endusers are placed in a situation where they must make decisions and manage the operation of their enterprises using a reallife ERP system (SAP), such as those used in large organizations. One key characteristic of ERPsim is that all decisions made by the participants must be entered into the ERP system and, in order to make those decisions, all of the information required must be extracted through standard reports of the ERP system. As such, one can think of ERPsim as a flight simulator for ERP system where end-users are flying a real corporate information system in a virtual business environment.

Until recently, ERPsim has been mainly used for end-user training purposes. More than 100 universities worldwide and numerous Fortune 1000 organizations are using ERPsim to train end-users in order to better understand the value of enterprise systems (more information is available at http://erpsim.hec.ca). In addition to its pedagogical applications, ERPsim can contribute to research on ERP-related concepts, using the simulator to gather data that were previously difficult to obtain. Cronan et al. (2009a, $2009 b)$ and Léger et al. $(2009,2010)$ are examples of studies using ERPsim to conduct experimental researches.

For NeuroIS researchers, ERPsim offers the possibility to collect neurophysiological data while subjects are immersed in a realistic business situation in which endusers are using an ERP system to make decisions and to resolve complex business problems. For example, it is possible to capture end-users' biosignals, such as electrodermal activity (EDA), electrocardiogram (ECG), facial electromyography (EMG), and electroencephalogram (EEG). In contrast to more sophisticated tools, such as fMRI, these neurophysiological techniques also objectively measure a user's behaviors and emotional reactions. However, compared to fMRI, neurophysiological techniques are less intrusive because participants in an experiment usually sit in front of computers in a normal environment rather than lying in a brain scanning machine (Riedl et al. 2010).

The biosignals derived from neurophysiological techniques can be triangulated against other empirical evidences, such as the usage data in the ERP system (i.e., clickstream data) and survey data. ERP systems, such as SAP, log all transactions performed by every users in the system. By mapping these different data sources (clickstream, survey, and biosignals) on the same timeline, it becomes possible to obtain a rich longitudinal dataset that includes the end-user's psychophysiological reactions during the ERP experience, the self-perceived attitudes and beliefs related to this interaction, as well as a detailed record of his actions and decisions executed in the ERP system during the experiment.

This effort in providing a methodological tool enabling multi-method experimental researches is consistent with the call for more triangulations in IT research and in the use of neurophysiological measurement tools to seek convergent validity of current IT psychometric tools (Dimoka et al. 2010). The main objective is not to replace the existing IT validated constructs, but to complement and enrich them with other sources of empirical evidences which were previously hard to collect in a valid and reliable way. This approach opens the door to investigations that were not previously possible.

In one of our current research programs, we are investigating the psychophysiological correlates of cognitive absorption (CA). This construct corresponds to a state of deep involvement with a software program and has theoretical roots in the concept of absorption (Tellegen and Atkinson 1974), the notion of flow (Csikszentmihalyi 1990), and the notion of cognitive engagement (Webster and Ho 1997). CA has widely been studied over the last decade in the IT literature using psychometric instrument developed by Agarwal and Karahanna (2000).

The paradox of measuring CA with psychometric tools is that it requires asking a subject to self evaluate the level of absorption over several Likert scale items. Obviously, such an approach implies the subject to be taken out of his cognitive absorption state in order to answer this survey. To circumvent this problem, researchers in the field of video game development have started using psychophysiological measures to infer the cognitive and emotional states of gamers. For example, Nacke (2009) reports correlations between ECG, EDA and EEG with a self-perceived game experience construct. Building on these approaches, our ongoing research investigates the correlation between several psychophysiological measures and the different dimensions of the CA construct, and our goal is to eventually try to predict perceptions 
of CA based on objective psychophysiological measurement.

The ERPsim research platform opens the possibility to triangulate many psychometric measures used in previous studies with neurophysiological signals addressing untapped research questions in IT. The ERPsim Lab is currently working on extending its platform to directly integrate the psychophysiological equipment of a Montréal-based company called Thought Technology Ltd. The objective is to ultimately provide the NeuroIS community with a flexible research tool to conduct experimental researches in complex IT environments, while collecting a rich set of data pertaining to the behaviors and emotions of users while interacting with IT.

Pierre-Majorique Léger Department of Information Technologies HEC Montréal, Canada

\section{References}

\section{to Sect. 1:}

Camerer C, Loewenstein GF, Prelec D (2005) Neuroeconomics: how neuroscience can inform economics. Journal of Economic Literature 43(1):9-64

Dimoka A, Pavlou PA, Davis FD (2007) NEUROIS: the potential of cognitive neuroscience for information systems research. In: Proceedings of the 28th international conference on information systems (ICIS), pp 1-20

\section{to Sect. 2:}

Birbaumer N, Ghanayim N, Hinterberger T, Iversen I, Kotchoubey B, Kübler A, Perelmouter J, Taub E, Flor H (1999) A spelling device for the paralysed. Nature 398:297298

Dornhege G, Millán JR, Hinterberger T, McFarland 'D, Müller K-R (2007) Toward brain-computer interfacing. MIT Press, Massachusetts

Müller-Putz GR, Scherer R, Pfurtscheller G, Neuper C (2010) Temporal coding of brain patterns for direct limb control in humans. Frontiers in Neuroscience 4:1-11

Pfurtscheller G, Müller-Putz GR, Scherer R, Neuper C (2008) Rehabilitation with braincomputer interface systems. Computer 41:58-65

Riedl R, Banker RD, Benbasat I, Davis FD, Dennis AR, Dimoka A, Gefen D, Gupta A, Ischebeck A, Kenning $P$, Müller-Putz G, Pavlou PA, Straub DW, vom Brocke J, Weber $B$ (2010a) On the foundations of NeurolS: reflections on the Gmunden Retreat 2009. Communications of the AIS 27:243-264
Riedl R, Hubert M, Kenning P (2010b) Are there neural gender differences in online trust? An fMRI study on the perceived trustworthiness of eBay offers. MIS Quarterly 34:397-428

Tan DS, Lee JC (2006) Using electroencephalograph signals for task classification and activity recognition. Microsoft Corporation, US Patent \& Trademark Office, Seria No. 349859, United States Patent Application No. 20070185697

Wolpaw JR, Birbaumer N, McFarland DJ, Pfurtscheller G, Vaughan TM (2002) Braincomputer interfaces for communication and control. Clinical Neurophysiology 113:767-791

\section{to Sect. 3 :}

Botvinick MM, Cohen JD, Carter CS (2004) Conflict monitoring and anterior cingulate cortex: an update. Trends in Cognitive Sciences 8(12):539-546

Gregor S (2006) The nature of theory in information systems. MIS Quarterly 30(3):611642

Gregor S, Jones D (2007) The anatomy of a design theory. Journal of the AIS 8(5):312 335

Haier RJ, Siegel BV, MacLachlan A, Soderling E, Lottenberg S, Buchsbaum MS (1992) Regional glucose metabolic changes af ter learning a complex visuospatial/motor task: a positron emission tomographic study. Brain Research 570(1-2):134-143

Hevner AR, March ST, Park J, Ram S (2004) Design science in information systems research. MIS Quarterly 28(1):75-105

March ST, Smith GF (1995) Design and natural science research on information technology. Decision Support Systems 15:251266

Riedl R, Banker RD, Benbasat I, Davis FD, Dennis AR, Dimoka A, Gefen D, Gupta $A$, Ischebeck $A$, Kenning $P$, Müller-Putz $G$ Pavlou PA, Straub DW, vom Brocke J, Weber $B(2010)$ On the foundations of NeurolS: reflections on the Gmunden Retreat 2009. Communications of the AIS 27:243-264

Riedl R (2009) Zum Erkenntnispotenzial der kognitiven Neurowissenschaften für die Wirtschaftsinformatik: Überlegungen anhand exemplarischer Anwendungen NeuroPsychoEconomics 4(1):32-44

Walls JG, Widmeyer GR, El Sawy OA (2004) Assessing information system design theory in perspective: how useful was our 1992 initial rendition? Journal of Information Technology Theory and Application 6(2):43-58

\section{to Sect. 4:}

Bagozzi RP (2007) The legacy of the technology acceptance model and a proposal for a paradigm shift. Journal of the AIS 8(4):244254

Dimoka A, Davis FD (2008) Where does TAM reside in the brain? The neural mechanisms underlying technology adoption. In: ICIS 2008 Proceedings, paper 169

Camerer C, Loewenstein G, Prelec D (2005) Neuroeconomics: how neuroscience can inform economics. Journal of Economic Literature 43(1):9-64

Fehr E, Schmidt KA (1999) Theory of fairness, competition and cooperation. Quarterly Journal of Economics 114:817-868
Ho T, Su X (2010) Peer induced fairness in games. American Economic Review (forthcoming)

Lieberman MD (2007) Social cognitive neuroscience: a review of core processes. Annual Review of Psychology 58:259-289

Venkatesh V, Davis FD, Morris MG (2007) Dead or alive? The development, trajectory and future of technology adoption research. Journal of the AIS 8(4):267-286

\section{to Sect. 5:}

Agarwal R, Karahanna E (2000) Time flies when you're having fun: cognitive absorption and beliefs about information technology. MIS Quarterly 24:665-694

Cronan TP, Douglas DE, Schmidt P, Alnuaime O (2009a) ERP simulation game; learning and attitudes toward SAP. Samples company 'First Time Hires'. ITRI-WP123-1009, Information Technology Research Institute, University of Arkansas

Cronan TP, Douglas DE, Schmidt $P$, Alnuaime O (2009b) Evaluating the impact of an ERP simulation game on student knowledge, skills, and attitudes. ITRI-WP123-1008, Information Technology Research Institute, University of Arkansas

Csikszentmihalyi M (1990) Flow: the psychology of optimal experience. Harper \& Row, New York

Dimoka A, Pavlou PA, Davis FD (2010) NeurolS: the potential of cognitive neuroscience for information systems research. Information Systems Research (forthcoming)

Léger P-M (2006) Using a simulation game approach to teach enterprise resource planning concepts. Journal of Information Systems Education 17:441-448

Léger P-M, Robert J, Babin G, Pellerin R, Wagner B (2007) ERPsim, ERPsim Lab (erpsim.hec.ca), HEC Montreal, Qc

Léger P-M, Babin G, Robert J, Pellerin R, Cassivi L, Hadaya P (2009) Assessing the impact of supply chain integration through an ERP system. In: International conference on ecommerce (ICEB 2009), Macau

Léger P-M, Charland P, Robert J, Babin G (2010) Using a business simulation game to develop IT competency. In: Temasek polytechnic international conference on learning and teaching, Singapour

Nacke L (2009) Affective ludology: scientific measurement of user experience in interactive entertainment. Blekinge Institute of Technology, Karlskrona

Riedl $R$, Banker RD, Benbasat I, Davis FD, Dennis AR, Dimoka A, Gefen D, Gupta $A$, Ischebeck A, Kenning $P$, Müller-Putz $G$, Pavlou PA, Straub DW, vom Brocke J, Weber $B(2010)$ On the foundations of Neurols: reflections on the Gmunden Retreat 2009. Communications of the AIS 27:243-264

Tellegen A, Atkinson G (1974) Openness to absorbing and self-altering experiences ("absorption"), a trait related to hypnotic susceptibility. Journal of Abnormal Psychology 83:268-277

Webster J, Ho H (1997) Audience engagement in multi-media presentations. The Database for the Advances in Information Systems 28:63-77 